\title{
AS SETE DÉCADAS DE 1984, DE GEORGE ORWELL: UM BREVE ESTUDO SOBRE A UTOPIA TOTALITÁRIA NO SÉCULO DAS DISTOPIAS
}

\section{THE SEVEN DECADES OF 1984, BY GEORGE ORWELL: A BRIEF STUDY ON A TOTALITARIAN UTOPIA IN THE CENTURY OF DYSTOPIAS}

\author{
Evanir Pavloski*
}

RESUMO: Em 2019, a primeira edição da obra distópica 1984, de George Orwell, completa setenta anos e, mesmo depois desse longo período, a relevância de diferentes questões suscitadas pela narrativa parece ser ainda mais evidente na contemporaneidade. Assim, o presente artigo tem por objetivo desenvolver uma análise do romance de Orwell, tendo em vista sua representatividade para as discussões estéticas e políticosociais que permearam todo século XX e que ainda ecoam no século XXI. Além disso, objetivamos enfatizar o caráter normalizador e autoritário da sociedade figurada pelo autor, aspecto que a notabiliza não apenas como uma reação ao universalismo do pensamento utópico tradicional, mas também como um olhar crítico sobre os regimes totalitários que emergiram ao longo do Novecentos.

Palavras-chave: Orwell; utopia; distopia; totalitarismo.

Aвstract: In 2019, the first edition of the dystopian work Ninety Eighty-Four, by George Orwell, completes seventy years and, despite that such a long period has passed; the relevance of different issues raised by the narrative is still more evident in contemporary times. Therefore, this article aims to present an analysis of Orwell's novel, considering its importance to the aesthetic and sociopolitical discussions that pervaded the $20^{\text {th }}$ century and still echo in the $21^{\text {st }}$ century. Furthermore, we aim to highlight the normative and authoritarian nature of the society depicted by the author, aspect that distinguishes the work not only as a reaction to the universalism of the tradition utopian thought, but also as a critical view on the totalitarian governments that emerged throughout the 1900's.

KEYwORDS: Orwell; utopia; dystopia; totalitarianism.

\footnotetext{
"Doutor em Estudos Literários pela Universidade Federal do Paraná (UFPR). Pós-Doutor em Teoria Literária pela Universidade de Campinas (UNICAMP). Professor adjunto do Departamento de Estudos da Linguagem da Universidade Estadual de Ponta Grossa (UEPG). Docente permanente do Programa de Mestrado em Estudos da Linguagem (UEPG). Email: evanir.pv@gmail.com
} 
Em sua obra Utopia: A história de uma ideia (2013), o professor Gregory Claeys afirma que as raízes do pensamento utópico se entrelaçam com as primevas narrativas míticas e as figuras de logos das primeiras religiões. De acordo com essa visão, a humanidade em sua busca pela compreensão do universo - tanto material quanto imaterial -, e por formas de representação ordenadoras da realidade sempre flertou com a sublimação de determinados espaços, seja para a reflexão sobre o presente, seja para a idealização de um futuro, que só se tornaria possível em outro plano de existência. Assim, a cosmogonia de Hesíodo, os Campos Elíseos descritos na Odisseia de Homero, a república de Platão e o Jardim do Éden cristão são projeções marcadas pelo signo da utopia, ainda que essa marca anteceda em século a criação do termo e a formalização literária do utopismo pela pena satírica de Thomas More.

Desde então, o vocábulo utopia passou por inúmeras resignificações semânticas e assumiu diferentes conotações simbólicas, tanto nas artes e na filosofia quanto na sociologia e na política. Não obstante essas constantes transformações, nota-se que o posicionamento crítico diante do se considera o real e o impulso ora renovador, ora escapista sempre foram características indeléveis do utopismo. Como afirma o crítico literário Alexander Swietochowski,

A utopia como a forma ideal de relações sociais é elemento o mais generalizado no mundo espiritual. Faz parte de todas as crenças religiosas, teorias morais e legais, sistemas de educação, criações poéticas, em uma palavra, de todo conhecimento e obra que visam oferecer modelos para a vida humana. É impossível imaginar qualquer época, nação ou mesmo indivíduo que não tenha sonhado com um céu na terra, que não tenha sido mais ou menos utópico. Onde quer que existam - e elas existem em toda parte - miséria, injustiça e dor, haverá também especulações sobre como erradicar as causas do mal. Na imensa escala que se estende por toda a história da cultura, desde as fantasias do nômade selvagem até as reflexões do filósofo moderno, encontra-se uma infinidade de versões da utopia. (SWIETOCHOWSKI. In: SZACHI, 1972, p. 8).

Especificamente na esfera da arte literária, o "lugar nenhum" descrito por More em $A$ utopia representou, na Era Moderna, o referente inicial de uma longa tradição de textos que viriam a problematizar o tempo presente por meio do contraste entre a realidade social de seus leitores e a projeção de um ethos ficcional considerado modelar. Como afirma Robert C. Elliot, "the portrayal of an ideal commonwealth has a double function: it establishes a standard, a goal; and by virtue of its existence alone it casts a critical light on society as presently constituted"1 (ELLIOT, 1970, p. 22).

${ }^{1}$ Tradução livre: A representação de uma sociedade ideal de riquezas comuns tem uma dupla função: estabelece um modelo, um objetivo; e pela virtude de sua existência única lança uma luz crítica sobre a sociedade constituída atualmente. 
Entretanto, a frustração com alguns dos rumos tomados pelo fluxo de transformações nos séculos XVIII e XIX², das quais redundou não apenas o enrijecimento de determinadas relações sociais, mas também a sensação de desapontamento com os ideais iluministas, fomentou a ascensão de um novo gênero na literatura: a utopia negativa ou distopia.

Para o Jerzy Szachi, as utopias positivas e negativas apresentam uma "consanguinidade" ideológica que as torna extensões de um mesmo posicionamento crítico e de semelhante processo criativo. Nas duas produções, ocorre a contraposição da realidade a um modelo social com o objetivo de incitar a reflexão sobre elementos do universo experimental, que eram vistos pelos respectivos autores como falhos. Tanto o idílio dos utopistas quanto o pesadelo dos distopistas insere o leitor num contexto de reavaliação conceitual ao colocá-lo diante de uma perspectiva radical e, em muitos casos, maniqueísta dos caminhos seguidos pelas sociedades históricas. "Nas utopias positivas contrasta-se a sociedade ideal, concebida mais ou menos em detalhe, com a sociedade má que é apreendida em geral em termos bastante sumários; com as utopias negativas é o inverso que ocorre". (SZACHI, 1972, p. 119).

Ainda que várias produções do gênero possam ser destacadas ainda no século XIX ${ }^{3}$, diante da vertiginosa renovação técnico-tecnológica e de um pessimismo social renovado e aguçado pela Primeira Grande Guerra, as distopias começam a ocupar um espaço de destaque no século XX. Em termos gerais, a distopia não é simplesmente a inversão dos idílios utópicos tradicionais, mas também a crítica veemente do caráter normalizador do utopismo em suas possibilidades de realização.

Daí o protesto - e as antiutopias - de Aldous Huxley, Orwell ou Zamiatin (na Rússia do início da década de 1920), que pintam um quadro horripilante de uma sociedade sem atritos em que as diferenças entre os seres humanos são, tanto quanto possível, eliminadas, ou pelo menos reduzidas, e o padrão multicolorido dos vários temperamentos, inclinações e ideais humanos - em suma, o próprio fluxo da vida - é brutalmente reduzido à uniformidade, aprisionado em uma camisa-de-força social e política que fere e estropia, terminando por esmagar os homens em nome de uma teoria monística, do sonho de uma ordem perfeita e estática. (BERLIN, 1991, p. 48-49).

A consolidação da literatura distópica envolve, em grande medida, a instrumentalização dos arquétipos e técnicas da ficção científica, as quais já influenciavam sensivelmente

\footnotetext{
${ }^{2}$ Isso não significa que o utopismo não sofreu críticas veementes ao longo de sua história. Há referentes, inclusive, já no século XVII de textos cujas reflexões se opunham à idealização utópica no pensamento social e na literatura. Citamos, por exemplo, a obra Mundus alter et idem, escrita por Joseph Hall e publicada em 1605.

${ }^{3}$ Ver A Sojourn in the City of Amalgamation, in the Year of Our Lord, 19- (1835), de Jerome B. Holgate; Vril-O poder da raça futura (1871); Planolândia (1884), de Edwin A. Abbott; A república do future (1887), de Ann Bowman Dodd e A nova utopia (1891) de Jerome K. Jerome.
} 
o utopismo tradicional. Ao figurar a ciência e a tecnologia como possíveis mecanismos de controle, as distopias desenvolvem uma potencialização negativa das sociedades modelares - o que as torna repelentes por envolver a imposição da ordem à custa da liberdade - criando projeções, majoritariamente prospectivas, que levam os leitores a vislumbrar as implicações das utopias e do cientificismo de modo mais concreto e, consequentemente, mais agudo.

Assim, é importante refletir sobre as características da ficção científica enquanto gênero literário, uma vez que esse gênero ao mesmo tempo tangenciou e foi tangenciado pela literatura distópica. A história que cerca essas criações artísticas acompanha o desenvolvimento do próprio conhecimento científico. À medida que novas descobertas e novos paradigmas surgiram no campo da ciência, novos horizontes temáticos se abriram para os autores, os quais se valiam de parte do processo de expansão das possibilidades de raciocínio e inventividade. Como afirmam Scholes e Rabkin sobre as raízes da ficção científica,

Like the history of science itself, the history of this literary form is thin and episodic until about four centuries ago, when the scientific method began to replace more authoritarian and dogmatic modes of thought, and people at last could see that the earth is not the center of the universe with the sun, moon, stars all spinning round it for the edification of mankind. ${ }^{4}$ (SCHOLES et RABKIN, 1977, p. 3).

Os autores salientam que dentre as possíveis características da ficção científica se destacam o poder emocional, a exigência intelectual e a consciência social dos textos. Eles acreditam também que, ao longo dos séculos, novos elementos foram incorporados ao gênero, plasmando um processo evolutivo coerente com o diversificado progresso científico, tecnológico e sociopolítico de cada época, tendência que se mantém estável até os dias atuais.

Dessa forma, a definição da ficção científica se torna muito abrangente, o que resulta na inclusão de uma considerável variedade de obras e autores. Segundo Rabkin, "a work belongs in the genre of science fiction if its narrative world is at least somewhat different from our own, and if that difference is apparent against the background of an organized body of knowledge"s (RABKIN, 1977, p. 119).

No caso das utopias positivas e negativas, Rabkin complementa o critério da inversão com o da extrapolação de características presentes no mundo factual. Nas produções utópicas e distópicas, as formas pelas quais essas ferramentas se apresentam são diversificadas e se

\footnotetext{
${ }^{4}$ Tradução livre: Como a história da própria ciência, a história dessa forma literária é escassa e episódica até por volta de quatro séculos atrás, quando o método científico começou a substituir modos de pensamento mais autoritários e dogmáticos, e as pessoas puderam finalmente ver que a Terra não é o centro do universo, com o Sol, a Lua, e estrelas todas girando em torno dela para a edificação da humanidade.

${ }^{5}$ Tradução livre: Uma obra pertence ao gênero da ficção científica se o seu mundo narrativo é de alguma forma diferente de nosso próprio mundo, e se essa diferença é aparente quando colocada contra um corpo organizado de conhecimento.
} 
concentram comumente sobre aspectos políticos, sociais e morais da sociedade como forma de estabelecer o contraste entre o universo empírico e o espaço ficcional.

Tendo em vista esses postulados teóricos, as obras de Zamiatin, Huxley e Orwell seriam representantes de uma das diversas linhas de composição ficcional que compõem a ficção científica. Nos três romances, a instrumentalização do aparato tecnológico pelo Estado desnuda a natureza totalitária dos regimes figurados e, em última análise, de aspectos do pensamento utópico criticado pelos autores.

Ao discorrer sobre a teoria do totalitarismo desenvolvida por Hanna Arendt, Margaret Canovan problematiza, a partir de critérios específicos, a instituição de um regime que preconiza a estabilidade social. Segundo ela, a tentativa de criar sociedades modelares pode ser vista como uma ruptura no fluxo de desenvolvimento dos grupos sociais, já que não apenas artificializa e desestrutura o papel dos indivíduos, tanto como cidadãos quanto como seres humanos, mas também transgride leis básicas da Natureza e da História. "According to those inexorable laws, human existence consists of the life or death struggle between collectivities - races or classes - whose motion is the real meaning of history [...] Neither stable institutions nor individual initiative can be allowed to get in the way of this frantic dynamism"6 (CANOVAN, 2000, p. 28).

Diante disso, as utopias, por meio da utilização maciça de instrumentos de controle, incluindo a ciência e a tecnologia, transformam o corpo social num objeto a ser moldado segundo diretrizes particulares que incluem a padronização dos comportamentos individuais e a universalização dos princípios que orientam o regime. Em outras palavras, os ideais do utopismo são entendidos pelos seus idealizadores como anseios universais, para a realização dos quais todos os indivíduos deveriam colaborar, espontaneamente ou não. Isaiah Berlin corrobora ironicamente essa afirmação assumindo o discurso de um utopista:

Como conheço o único caminho verdadeiro até a solução definitiva dos problemas da sociedade, sei como conduzir a caravana humana; e já que você ignora o que sei, não lhe é permitido ter a liberdade de escolha, mesmo dentro dos limites mais estritos, se o objetivo deve ser alcançado. Você afirma que uma determinada política poderá fazê-lo mais feliz, ou mais livre, ou lhe permitir respirar; mas sei que você está enganado, conheço suas necessidades, as necessidades de todos os homens; e, se houver resistência baseada na ignorância ou na malevolência, então ela deve ser vencida, e centenas de milhares poderão perecer para tornar milhões felizes para todo o sempre. (BERLIN, 1991, p. 24).

\footnotetext{
${ }^{6}$ Tradução livre: De acordo com tais leis inexoráveis, a existência humana consiste na luta de vida ou morte entre coletividades - raças ou classes - cujo movimento é o verdadeiro sentido da história [...] Nem instituições estáveis nem a iniciativa individual podem interferir nessa dinâmica frenética.
} 
O acúmulo de poder resultante desse processo constitui as bases do governo totalitário, que tem como objetivo não apenas a realização de um ideal supostamente coletivo, mas também a estabilidade da estrutura social implantada. Nesse contexto, os indivíduos são reduzidos a componentes estruturais da sociedade e cerceados em seu direito de opinar sobre os próprios destinos. Para Hannah Arendt, esse aspecto corresponde a um substancial retrocesso da humanidade em sua evolução histórico-social.

Total power can be achieved and safeguarded only in a world of conditioned reflexes, of marionettes without the slightest trace of spontaneity. Precisely because man's resources are so great, he can be fully dominated only when he becomes a specimen of the animal-species man. ${ }^{7}$ (ARENDT, 1967, p. 457).

Esse modelo de sociedade utopicamente totalitária é o ponto de partida para a ferina sátira da maioria dos distopistas. Esses autores, ao conceberem os seus modelos, priorizam alguns elementos dos textos utópicos que revelam o caráter essencialmente disciplinar dessas idealizações. Luiz Costa Lima afirma que

No mundo contemporâneo, a arte (não só a literatura) apenas contém um potencial de negatividade: a de revelar os limites dos projetos e dos sistemas, a de ironizar as boas intenções (e, no entanto, necessárias), a de parodiar os construtores do futuro, ainda quando aceite que algum futuro outro precisa ser construído. Tudo isso porque já não reconhecemos uma solução que seja em bloco positiva. (LIMA, 1986, p. 71).

Assim, três obras referenciais desse gênero no século XX compartilham como característica principal de suas figurações o rígido controle exercido institucionalmente sobre os indivíduos. Zamiatin, Huxley e Orwell figuram sociedades nas quais a estabilidade foi indiscutivelmente alcançada, tendo como custo, entretanto, a erradicação da liberdade individual. Poderíamos dizer que a distopia delineia com traços fortes a tendência totalitária que aparece de forma latente nas idealizações consideradas positivas. Jenni Calder salienta que,

Brave New World and Nineteen Eighty-Four are usually placed in the category of anti-utopian ${ }^{8}$ fiction, nightmares not dreams, warnings

\footnotetext{
${ }^{7}$ Tradução livre: O poder total somente pode ser atingido e resguardado num mundo de reflexos condicionados, de marionetes sem o menor traço de espontaneidade. Exatamente porque os recursos humanos são tão grandes, o homem só pode ser completamente dominado quando ele se torna um espécime da espécie homem-animal.

${ }^{8}$ É importante esclarecer que entendemos os termos distopia, antiutopia e utopia negativa como termos semanticamente equivalentes e intercambiáveis, utilizados para se referir a um gênero literário definido pela sua visão satírica dos textos utópicos. Tal entendimento encontra ressonância na reflexão de Gregory Claeys na obra The Cambridge Companion to Utopian Literature (2010), na qual o professor afirma que 'Dystopia' is often used interchangeably with 'anti-utopia' or 'negative utopia', by contrast to utopia or 'eutopia' (good place), to describe a fictional portrayal of a society in which, or negative social and political developments, have the upper hand, or as a satire of utopian aspirations" (Tradução livre: $O$
} 
not portraits of an ideal. Yet both were aware that there existed as they were writing processes of thought and action that could lead to what they described, and people who were more than ready to make human sacrifices in order to achieve progress or power. Progress and idealism have always attracted the human race. To be unable to believe that things can and will get better is at best negative, at worst destructive. But to believe that the realization of an ideal is worth any sacrifice, or that progress by its very nature must be good for humanity, is extremely dangerous. ${ }^{9}$ (CALDER, 1976, p. 7).

Abordando com mais especificidade os objetivos deste artigo, é importante considerar que o romance 1984 apresenta características particulares que merecem destaque dentre as obras do gênero produzidas no último século. Primeiramente, é preciso considerar o momento histórico no qual a narrativa foi produzida. Os profundos traumas causados em toda a Europa pelo recente conflito mundial e a revelação dos horrores praticados pelos governos totalitários influenciaram, indubitavelmente, o ponto de vista apresentado no romance ${ }^{10}$. Sobre a dicção de Orwell no romance, Jenni Calder afirma que

If Huxley was sceptical in 1930 when he wrote Brave New World, Orwell had almost given up hope in 1948 when he wrote Nineteen Eighty-Four. Orwell saw power politics, not science, as the major threat to mankind, and he had had over the previous twelve years or so plenty of opportunity to savour the possibilities of power. In Nineteen Eighty-Four he was coping with both a personal and a public depression. His hopes of social revolution now seemed to him illusory. There was a brief period during the war when he had thought there was a genuine movement towards equality, and this had sustained him, but what he saw in the post-war period was defeat in the ashes of victory. ${ }^{11}$ (CALDER, 1976, p. 8).

termo distopia é comumente utilizado de forma intercambiável com 'antiutopia' ou 'utopia negativa', em contraste aos termos utopia ou 'eutopia' (bom lugar) para descrever uma representação ficcional de uma sociedade, na qual desenvolvimentos sociais e políticos negativos tiveram sucesso, ou para satirizar aspirações utópicas).

${ }^{9}$ Tradução livre: Admirável Mundo Novo e 1984 são comumente categorizados como ficção antiutópica, pesadelos, não sonhos; avisos, não representações de um ideal. Entretanto, os dois autores estavam conscientes de que existiam, no período em que escreviam, tendências de pensamento e ação que poderiam levar àquilo que eles descreveram e pessoas mais do que prontas para fazer sacrifícios humanos no intuito de alcançar progresso ou poder. Progresso e idealismo sempre atraíram a raça humana. A incapacidade de acreditar que as coisas podem ser melhores e serão é, no melhor dos casos, negativa; no pior dos casos, destrutiva. Mas acreditar que a realização de um ideal justifica qualquer sacrifício, ou que o progresso em si deve ser bom para a humanidade, é extremamente perigoso.

${ }^{10} \mathrm{O}$ comentário de Luiz Costa Lima sobre o posicionamento de Auerbach após o final da Segunda Guerra Mundial exemplifica as reflexões que permeavam esse período: "No final de sua vida, terminada a Segunda Grande Guerra, Auerbach tinha consciência de que o ocaso de uma época se aproximava. A sociedade contemporânea, por ambos os blocos, o capitalista e o socialista, parecia se encaminhar a um forte modelo de estandardização" (LIMA, 1986, p. 419).

${ }^{11}$ Tradução livre: Se Huxley estava cético em 1930 quando ele escreveu Admirável Mundo Novo, Orwell tinha quase desistido de ter esperança em 1948 quando escreveu 1984. Orwell via o poder político, não a ciência, como a grande ameaça para a humanidade e nos últimos vinte anos tivera inúmeras oportunidades de verificar a força do poder. Em 1984 ele estava 
Assim como em Nós e Admirável Mundo Novo, o protagonista em 1984 é visivelmente inadequado para o tipo de sociedade figurada. Sua individualidade e sua consciência crítica o transformam em um estranho dentro de seu próprio mundo. A sua revolta solitária serve, em grande medida, para salientar não apenas o nível de controle exercido pelo Estado, mas também o grau de inconsciência a qual os indivíduos devem ser submetidos em nome do equilíbrio na Oceania. Nesse contexto, Winston Smith tenta preservar a liberdade no único espaço que lhe resta: sua própria mente. Entretanto, o poder exercido na distopia orwelliana ultrapassa o plano físico e atinge camadas mais profundas da psique humana. Como afirma a personagem O’ Brien ao dirigir-se ao próprio Winston: “a segunda coisa que deves entender é que poder é o poder sobre todos os entes humanos. Sobre o corpo, mas, acima de tudo, sobre a mente. O poder sobre a matéria, realidade externa, como a chamarias, não é importante. $\mathrm{E}$ o nosso poder sobre a matéria já é absoluto" (ORWELL, 2003, p. 252).

O próprio George Orwell, em um de seus comentários sobre o fim da Segunda Guerra Mundial, afirma que "the greatest mistake is to imagine that the human being is an autonomous individual. The secret freedom which you can supposedly enjoy under a despotic government is nonsense, because your thoughts are never entirely your own"12 (ORWELL, 1945. In: ORWELL \& ANGUS, vol. 03, 1968, p. 133).

A iminente derrota do protagonista ao final da narrativa potencializa o grau de eficiência dos mecanismos coercitivos utilizados pelo Partido, além de ressaltar a impotência do indivíduo comum diante do totalitarismo utópico. Essa perspectiva é recorrente na literatura de Orwell e foi de certa forma confirmada pela ascensão dos regimes centralizadores do século XX. Jeffrey Meyers salienta que:

Winston Smith, the final embodiment of defeated man, has predecessors in all of Orwell's books: in his impoverished and exploited personae in Paris, London, Wigan and Spain; in Flory, Dorothy Hare, Gordon Comstock, George Bowling and Boxer [...] And each character struggles against the bondage of his threatening world toward individual freedom and responsibility. ${ }^{13}$ (MEYERS, 1975, p. 153-154).

\footnotetext{
enfrentando ao mesmo tempo uma depressão pessoal e pública. As suas esperanças na revolução social pareciam agora ilusórias. Houve um período breve durante a guerra quando ele pensou que havia um movimento genuíno em direção da igualdade e isso o animou, mas o que ele viu no período pós-guerra foi a derrota nas cinzas da vitória.

${ }^{12}$ Tradução livre: O grande erro é imaginar que o ser humano é um indivíduo autônomo. A liberdade secreta que você pode supostamente aproveitar sob um governo despótico é um absurdo porque os seus pensamentos não são nunca completamente seus.

${ }^{13}$ Tradução livre: Winston Smith, a corporificação final do homem derrotado, tem predecessores em todos os livros de Orwell: na personae empobrecida e explorada que ele assume em Paris, Londres, Wigan e Espanha; em Flory, Dorothy Hare, Gordon Comstock, George Bowling and Boxer [...] E cada personagem de Orwell luta contra as amarras de seu mundo ameaçador pela liberdade e responsabilidade individual.
} 
Se considerarmos que a rígida estrutura disciplinar figurada em 1984 corresponde, em grande parte, a uma extrapolação de aspectos dos regimes totalitários do universo factual, torna-se necessário analisar como tais elementos se organizam nas sociedades históricas. Para tanto, os trabalhos de Michel Foucault são de grande valia para nossa discussão, uma vez que desvelam a evolução dos mecanismos de controle, os quais são herdados pelos totalitarismos do Noventos.

Foucault salienta que a valorização do controle sobre o indivíduo surge como um aprimoramento das práticas desenvolvidas pelos Estados monárquicos desde a Idade Média. Com o progressivo desenvolvimento dos meios de produção, as relações entre indivíduos e, em sentido mais amplo, a própria estrutura social, sofrem alterações profundas que demandam uma reorganização na maneira pela qual o poder é exercido. A soberania começa a ser vista como uma forma de autoridade ultrapassada, tendo em vista o horizonte de possibilidades criado pelas constantes inovações técnicas.

Com efeito, o modo pelo qual o poder era exercido podia ser transcrito, ao menos no essencial, nos termos da relação soberano-súdito. Mas, nos séculos XVII e XVIII, ocorre um fenômeno importante: o aparecimento, ou melhor, a invenção de uma nova mecânica de poder, com procedimentos específicos, instrumentos totalmente novos e aparelhos bastante diferentes, o que é absolutamente incompatível com as relações de soberania. (FOUCAULT, 1981, p. 187).

Tais transformações são complementadas pela assimilação por parte dos governos de concepções que situam o indivíduo como o objeto central das preocupações e precauções estatais. Se na sociedade feudal o controle dos bens materiais era suficiente para garantir a estabilidade do regime, com a ascensão da burguesia, o fortalecimento da mobilidade social e a valorização da liberdade individual provocam um deslocamento dos dispositivos de controle.

Em outras palavras, a relação de soberania quer no sentido amplo quer no restrito, recobria a totalidade do corpo social [...] Este novo mecanismo de poder apoia-se mais nos corpos e seus atos do que na terra. É um mecanismo que permite extrair dos corpos tempo e trabalho mais do que bens e riqueza. É um tipo de poder que se exerce continuamente através da vigilância e não descontinuamente por meio de sistemas de taxas e obrigações distribuídas no tempo; que supõe mais um sistema minucioso de coerções materiais do que a existência física de um soberano. (FOUCAULT, 1981, p. 187-188).

A afirmação acima aponta para elementos apreensíveis na distopia orwelliana. $\mathrm{Na}$ sociedade de 1984 a presença física de um soberano é substituída por uma imagem que representa a encarnação dos princípios que regem todos os indivíduos: o Grande Irmão. Tais 
diretrizes servem como base para o desenvolvimento de uma abrangente rede de relações coercitivas que se manifestam por meio de dispositivos, discursos e condicionamentos tanto físicos quanto psicológicos.

Segundo Foucault, esse novo tipo de poder, ao contrário da estagnação característica da soberania, apresenta uma constante busca pela especialização dos mecanismos disciplinares, que prioriza o aumento não apenas do seu alcance, mas também da sua eficiência. $O$ sistema nunca para de se renovar e de evoluir. "Finalmente, ele se apoia no princípio, que representa uma nova economia do poder, segundo o qual se deve propiciar simultaneamente o crescimento das forças dominadas e o aumento de força e da eficácia de quem as domina" (FOUCAULT, 1981, p. 188).

Na sociedade ficcional de George Orwell, o progressivo desenvolvimento do aparato controlador é evidente. A evolução contínua aponta para a consolidação do poder nas mãos do Partido e a completa supressão das individualidades. Podemos citar como exemplo as contínuas pesquisas desenvolvidas na área da linguística com o intuito de estabelecer os parâmetros de uma língua artificial, que impossibilitaria a veiculação de ideias heterodoxas e, consequentemente, tornaria inviável a própria concepção de tais pensamentos. "A Revolução se completará quando a língua for perfeita. Novilíngua é Ingsoc e Ingsoc é Novilíngua” (ORWELL, 2003, p. 54).

Para Foucault, a definição de um modelo de conduta a ser imposto ao corpo social supera, em termos práticos, os códigos legais escritos para regulamentar as relações humanas dentro do grupo. Nas sociedades disciplinares os indivíduos são direcionados por um conjunto de normas desvinculadas da esfera das leis escritas.

As disciplinas são portadoras de um discurso que não pode ser o do direito; o discurso da disciplina é alheio ao da lei e da regra enquanto efeito da vontade soberana. As disciplinas veicularão um discurso que será o da regra, não da regra jurídica derivada da soberania, mas o da regra "natural", quer dizer, da norma; definirão um código que não será o da lei mas o da normalização; referir-se-ão a um horizonte teórico que não pode ser de maneira alguma o edifício do direito mas o domínio das ciências humanas; a sua jurisprudência será a de um saber clínico. (FOUCAULT, 1981, p. 189).

Já no início da narrativa orwelliana, o protagonista Winston Smith deixa claro que, desde a revolução promovida pelo Partido, o código legal foi substituído por um modelo comportamental de base ideológica a ser rigidamente seguido por todos os cidadãos. As severas punições impingidas sobre aqueles que se desviam da norma estabelecida tendem muito mais para a eliminação dos sujeitos do que para a correção de suas atitudes. "O que agora se dispunha a fazer era abrir um diário. Não era um ato ilegal (nada mais era ilegal, pois não havia mais 
leis), porém, se descoberto, havia razoável certeza de que seria punido, por pena de morte, ou no mínimo vinte e cinco anos num campo de trabalhos forçados" (ORWELL, 2003, p. 10).

No universo ficcional de 1984, os ideocriminosos, como Winston, podem ser compreendidos metaforicamente como células defeituosas de um organismo estável e uniforme, de forma que a cura é alcançada por meio de violentas práticas corretivas ou pela simples extração dos elementos considerados "doentes". Seja qual for o método escolhido, a prioridade do Estado é evitar a todo custo que a infecção da heterodoxia se alastre para outros componentes do corpo social e desestabilize a harmonia construída pelo Partido.

É preciso considerar, contudo, que o poder exercido nas sociedades disciplinares não se manifesta unilateralmente, mas por uma multiplicidade de discursos e de ações coercitivas disseminadas pelos próprios indivíduos. O controle não é apenas impositivo, mas aceito e redistribuído. Assim que um ideal de cidadão é constituído e aceito pela população, os membros do grupo são levados não apenas a apoiar, mas também a proteger a integridade do modelo. Ao discorrer sobre a dinâmica do poder em diferentes estruturas, Foucault salienta:

É evidente que, em um dispositivo como um exército ou uma oficina, ou um outro tipo de instituição, a rede de poder possui uma forma piramidal. Existe portanto um ápice; mas, mesmo em um caso tão simples como este, este "ápice" não é a "fonte" ou o "princípio" de onde todo o poder derivaria como um foco luminoso (esta é a imagem que a monarquia faz dela própria). $\mathrm{O}$ ápice e os elementos inferiores da hierarquia estão em uma relação de apoio e de condicionamento recíprocos; eles se "sustentam". (FOUCAULT, 1981, p. 221).

Essa sustentação hierárquica se manifesta na distopia de Orwell a partir do acentuado grau de insegurança que permeia quase todos os níveis da sociedade. A homogeneização ideológica faz com que cada sujeito participe ativamente na detecção e delação de quaisquer desvios de conduta. Foucault aponta precedentes históricos para esse tipo de relação disciplinar entre indivíduos de um mesmo grupo:

No sistema inglês do século XVIII o controle é exercido pelo grupo, sobre um indivíduo ou sobre indivíduos pertencentes a este grupo. Esta era a situação ao menos em seu momento inicial no fim do século XVII e início do século XVIII. [...] Só mais tarde é que as instâncias deslocaram-se para cima e para o Estado. Era o fato de um indivíduo pertencer a um grupo que fazia com que ele pudesse ser vigiado e vigiado pelo próprio grupo. (FOUCAULT, 1996, p. 111)

Em 1984, não resta ao indivíduo espaço possível de exercício da liberdade além das colunas do Partido ou dos muros cuidadosamente erguidos em sua própria consciência. Consequentemente, para Winston Smith o processo de dissimulação é tão importante quanto 
o enclausuramento de sua individualidade. A personagem, ao comentar sobre o seu rápido, mas marcante encontro com O' Brien durante os Dois Minutos de Ódio, enfatiza que: “Durante um segundo, dois, haviam trocado um olhar equívoco, e era o fim da história. Mas até aquilo era um acontecimento memorável, na solidão amuralhada em que se era obrigado a viver" (ORWELL, 2003, p. 20).

A partir disso, poderíamos dizer que na sociedade oceânica o indivíduo não é levado à prisão, mas a prisão é incorporada à sua vida. Remetemo-nos então ao conceito de reclusão discutido por Michel Foucault. Para o autor, o desenvolvimento e a especialização de instituições essencialmente disciplinares possibilita um processo de inclusão dos sujeitos em espaços rigidamente controlados que consolidam o processo de normalização.

$\mathrm{Na}$ época atual, todas essas instituições - fábrica, escola, hospital psiquiátrico, hospital, prisão - têm por finalidade não excluir, mas ao contrário, fixar os indivíduos [...] Mesmo se os efeitos dessas instituições são a exclusão do indivíduo, elas têm como finalidade primeira fixar os indivíduos em um aparelho de normalização dos homens. (FOUCAULT, 1996, p. 114).

Assim, Foucault aponta uma nova forma de controle e correção que, a partir do século XIX, ultrapassa os limites das celas. O condicionamento dos indivíduos passa a se instalar nos múltiplos espaços compartilhados, de forma que o mecanismo se torna mais eficiente e mais abrangente. Ao participarem do grupo ou ao se filiarem a uma instituição, os sujeitos assumem o modelo comportamental definido pela sociedade, o que facilita a estandardização de todo o corpo social.

Pode-se, portanto, opor a reclusão do século XVIII, que exclui os indivíduos do círculo social, à reclusão que aparece no século XIX, que tem por função ligar os indivíduos aos aparelhos de produção, formação, reformação ou correção de produtores. [...] Eis porque oporei a reclusão ao sequestro; a reclusão do século XVIII, que tem por função essencial a exclusão dos marginais ou o reforço da marginalidade, e o sequestro do século XIX que tem por finalidade a inclusão e a normalização. (FOUCAULT, 1996, p. 114).

Gilles Deleuze corrobora a reflexão de Foucault e aponta, a partir de exemplos cotidianos, a constante movimentação dos indivíduos de um espaço normalizante para outro. A sucessão desses ambientes remonta, em termos específicos para cada um deles, as características das instituições de punição, correção e confinamento. O autor afirma que:

O indivíduo não cessa de passar de um espaço fechado a outro, cada um com suas leis: primeiro a família, depois a escola ("você não está mais na sua família"), depois a caserna ("você não está mais na escola"), 
depois a fábrica, de vez em quando o hospital, eventualmente a prisão, que é o meio de confinamento por excelência. (DELEUZE, 1992, p. 219).

Em 1984, todos os ambientes pelos quais Winston transita são rigidamente organizados e controlados a fim de extrair dos indivíduos não apenas obediência, mas também tempo e trabalho. Em seu trabalho, por exemplo, o protagonista participa do processo de reconstrução da história alterando informações e textos que perderam a sua validade ou a relevância para os interesses do Partido. Tal tarefa exige um elevado grau de ortodoxia para que o trabalhador não reconheça na falsificação que acaba de realizar qualquer traço de falsidade. Assim, Winston assume diariamente o padrão de comportamento previsto pela norma aceita socialmente.

Além disso, como membro do Partido Externo, a personagem deve participar de certas reuniões públicas e desenvolver certas atividades "voluntárias" que comprovam a sua lealdade ao regime. Em outras palavras, quanto mais o protagonista se inclui nas instituições da sociedade oceânica, mais ele é forçado a aceitar a normalização que regula esses espaços, processo imperativo para a sua própria segurança. As reservas de Winston em relação ao abandono de alguns dos seus compromissos públicos exemplificam a importância desse paradigma comportamental:

Era a segunda vez em três semanas que faltava a um sarau no Centro Comunal: gesto audacioso, pois podia ter a certeza de que era cuidadosamente verificado o número de presenças no Centro. Em princípio, um membro do Partido não tinha horas vagas, e não ficava nunca só, exceto na cama. Supunha-se que quando não estivesse trabalhando, comendo ou dormindo, devia participar de alguma recreação comunal; era sempre ligeiramente perigoso fazer qualquer coisa que sugerisse $o$ gosto pela solidão, mesmo que fosse apenas passear sozinho. (ORWELL, 2003, p. 83).

Em sua obra Vigiar e Punir, Foucault analisa esses mínimos processos que, diariamente e, muitas vezes, imperceptivelmente consolidam a disciplina e expandem os efeitos do poder sobre todo o corpo social:

Técnicas sempre minuciosas, muitas vezes íntimas, mas que têm a importância: porque definem um certo modo de investimento político e detalhado do corpo, uma nova "microfísica" do poder; e porque não cessaram, desde o século XVII, de ganhar campos cada vez mais vastos, como se tendessem a cobrir o corpo social inteiro [...] A disciplina é uma anatomia do detalhe. (FOUCAULT, 1984, p. 128).

Além dos aspectos apontados até aqui, a vigilância permanente constitui um elemento fundamental tanto para a teoria das sociedades disciplinares de Foucault quanto para a análise do espaço ficcional de 1984. Para o historiador e filósofo francês, aquilo que por ele é 
caracterizado como o "olho do poder" (FOUCAULT, 1981, p. 209) representa a grande inovação dos regimes do século XIX em relação aos governos monárquicos. O autor afirma que a imposição de um poder central baseado unicamente na violência não alcança a estabilidade desejável devido ao clima de revolta e insubordinação consequentemente gerado. Além disso, o mecanismo da repressão violenta não é apenas oneroso, mas também produz resultados irregulares a partir do seu princípio de punição exemplar.

Se a violência for grande, há o risco de provocar revoltas; ou, se a intervenção for muito descontínua, há o risco de permitir o desenvolvimento, nos intervalos, dos fenômenos de resistência, de desobediência, de custo político elevado. Era assim que funcionava o poder monárquico. Por exemplo, a justiça só prendia uma proporção irrisória de criminosos; ela se utilizava do fato para dizer: é preciso que a punição seja espetacular para que os outros tenham medo. Portanto, poder violento e que devia, pela virtude de seu exemplo, assegurar funções de continuidade. A isto os novos teóricos do século XIX respondem: é um poder muito oneroso e com poucos resultados. (FOUCAULT, 1981, p. 217).

Dessa forma, a vigilância se tornou o mecanismo apropriado para aumentar a eficácia do controle exercido pelo Estado e, ao mesmo tempo, resguardar os cofres públicos. O exercício do poder deixa de atacar apenas os corpos e passa a se concentrar na força silenciosa do olhar alheio. Como enfatiza Foucault,

Já o olhar vai exigir muito pouca despesa. Sem necessitar de armas, violências físicas, coações materiais. Apenas um olhar. Um olhar que vigia e que cada um, sentindo-o pesar sobre si, acabará por interiorizar, a ponto de observar a si mesmo; sendo assim, cada um exercerá esta vigilância sobre e contra si mesmo. Fórmula maravilhosa: um poder contínuo e de custo afinal de contas irrisório. (FOUCAULT, 1981, p. 218).

Como forma de aprofundar suas reflexões, Michel Foucault estabelece relações entre as estruturas disciplinares do século XIX e a construção utópica idealizada pelo francês Jeremy Bentham no século XVIII: o Panóptico. Esse projeto propõe uma nova dinâmica do poder, baseada na ininterrupta observação e normalização dos indivíduos que estejam inseridos em sua estrutura. No prefácio de sua obra, Bentham afirma que "trata-se de um novo modo de garantir o poder da mente sobre a mente, em um grau nunca antes demonstrado; e em um grau igualmente incomparável, para quem o assim desejar, de garantia contra o exagero. Esse é o mecanismo, esse é o trabalho que pode ser feito com ele" (BENTHAM, 2000, p. 15).

Os possíveis usos e resultados dessa estrutura de vigilância são múltiplos e podem variar desde a correção institucional de desvios aparentes na sociedade até a canalização da força de trabalho dos indivíduos para os meios de produção. 
Não importa quão diferentes, ou até mesmo quão opostos, sejam os propósitos: seja o de punir o incorrigivel, encerrar o insano, reformar o viciado, confinar o suspeito, empregar o desocupado, manter o desassistido, curar o doente, instruir os que estejam dispostos em qualquer ramo da indústria, ou treinar a raça em ascensão no caminho da educação. (BENTHAM, 2000, p. 17).

Tal perspectiva se encaixa apropriadamente na discussão foucaultiana sobre a qual viemos nos reportando. As estruturas disciplinares do século XIX englobam os mesmos objetivos do Panóptico, ampliando-os, entretanto, para todas as esferas da sociedade. Foucault afirma que

Já nas instâncias de controle que surgem a partir do século XIX, o corpo adquire uma significação totalmente diferente; ele não é mais o que deve ser supliciado, mas o que deve ser formado, reformado, corrigido, o que deve adquirir aptidões, receber um certo número de qualidades, qualificar-se como corpo capaz de trabalhar. ${ }^{14}$ (FOUCAULT, 1996, p. 119).

Segundo Bentham, o Panóptico seria um edifício circular, sendo que os apartamentos ou celas dos prisioneiros ocupariam a circunferência com aberturas tanto para o interior quanto para o exterior da construção. No centro desse círculo seria construída uma torre onde se postaria o inspetor ou vigilante. Por meio da iluminação natural proveniente das duas aberturas de cada cela, o encarregado da vigilância poderia visualizar o interior de todas as celas e, consequentemente, todas as ações dos indivíduos poderiam ser registradas. Os ocupantes do edifício seriam impedidos de se comunicar uns com outros. Para tanto, partições seriam instaladas em todas as celas como forma de impossibilitar a visão e o diálogo entre os indivíduos. Além disso, o inspetor necessita de um mecanismo que possibilite não apenas a rápida comunicação com cada um dos ocupantes das celas, mas também a perenidade, ainda que ilusória, da observação ininterrupta. Bentham propõe que,

Para poupar o esforço problemático de voz que poderia, de outro modo, ser necessário, e para impedir que um prisioneiro saiba que o inspetor está ocupado, a distância, com outro prisioneiro, um pequeno tubo de metal deve ir de uma cela ao alojamento do inspetor, passando através da área, indo, assim, até o lado da janela correspondente do alojamento. Por meio desse implemento, o menor murmúrio de um pode ser ouvido

\footnotetext{
${ }^{14} \mathrm{Na}$ obra Vigiar e Punir, Foucault propõe um exemplo da aplicação dos princípios do Panóptico a partir do espaço de uma oficina: "Percorrendo-se o corredor central da oficina, é possível realizar uma vigilância ao mesmo tempo geral e individual; constatar a presença, a aplicação do operário, a qualidade de seu trabalho; comparar os operários entre si, classificá-los segundo a sua habilidade e rapidez; acompanhar os sucessivos estágios de fabricação. Todas essas seriações formam um quadriculado permanente: as confusões se desfazem" (FOUCAULT, 1984, p. 133).
} 
pelo outro, especialmente se ele for orientado a aplicar seu ouvido ao tubo. (BENTHAM, 2000, p. 19).

A disposição desses tubos serviria também como meio de propagação da voz do instrutor para a prática corretiva daqueles sob sua responsabilidade. $O$ direcionamento e a fiscalização da produtividade de cada indivíduo poderiam ser facilmente controlados tanto pelo olhar, que não encontraria obstáculos visuais nos diversos alojamentos que o circunda, quanto pela voz que poderia ser distribuída igualmente em todas as direções.

É importante salientar que Bentham previa em seu projeto o desenvolvimento de um processo de vigilância mútua entre os indivíduos, que não diminuiria a importância do papel do inspetor, mas o complementaria. Segundo o autor, essa atividade seria realizada espontaneamente pelos membros do grupo, de maneira quase instintiva.

Para que elas se entreguem a essa atividade de vigilância, nem sequer será necessário que o inspetor lhes dê qualquer ordem particular nesse sentido. Segregadas às vezes por sua situação, de qualquer outro objeto, elas darão a seus olhos, naturalmente, e de uma forma inevitável, uma direção que se conformará àquele propósito, em qualquer intervalo momentâneo de suas ocupações cotidianas. Essa atividade tomará, em seu caso, o lugar daquela grande e constante ocasião de distração do sedentário e do desocupado em pequenas cidades - o ficar olhando pela janela. (BENTHAM, 2000, p. 26).

Michel Foucault salienta a eficiência e a inovação trazida pelo modelo do Panóptico. Embora acredite que a pura vigilância não constitua o único e mesmo o principal mecanismo de controle das sociedades disciplinares, afirma que vários aspectos inerentes às estruturas normalizadoras do século XIX foram espacializados de maneira funcional por Bentham. "Ele descreve na utopia de um sistema geral, mecanismos específicos que realmente existem" (FOUCAULT, 1981, p. 227).

Para o autor, o edifício utópico evidencia uma nova dinâmica do poder que vem substituir a centralização dos regimes monárquicos.

Não se tem neste caso uma força que seria inteiramente dada a alguém e que este alguém exerceria isoladamente, totalmente sobre os outros; é uma máquina que circunscreve todo mundo, tanto aqueles que exercem o poder quanto aqueles sobre os quais o poder se exerce. [...] O poder não é substancialmente identificado com um indivíduo que o possuiria ou que o exerceria devido ao seu nascimento; ele torna-se uma maquinaria de que ninguém é titular. Logicamente, nesta máquina ninguém ocupa o mesmo lugar; alguns lugares são preponderantes e permitem produzir efeitos de supremacia. De modo que eles podem assegurar uma 
dominação de classe, na medida em que dissociam o poder do domínio individual. (FOUCAULT, 1981, p. 219).

George Orwell utiliza como base para a sua sociedade distópica aspectos que podem ser encontrados tanto na obra de Bentham quanto nas de Foucault, o que demonstra, por um lado, o diálogo epistêmico do autor com o passado; e, por outro lado, a representatividade de temas abordados em seu romance, os quais são discutidos por intelectuais posteriores como Foucault e continuam a se inscrever nas pautas de diferentes comunidades argumentativas.

Na Oceania, a vigilância é um elemento de fundamental importância para a estabilidade do regime: a normalização dos indivíduos é fiscalizada e, em termos mais amplos, sustentada pela contínua observação dos atos mais sutis e das palavras mais frívolas. Além disso, todos os ambientes, compartilhados ou particulares, servem como espaços de análise comportamental e ideológica. Nesse sentido, o universo pessoal dos cidadãos da Oceania equivaleria à vida nas celas do Panóptico.

No universo ficcional, o olhar do inspetor é substituído por aparelhos que captam, ao mesmo tempo, sons e imagens: as teletelas. Por meio delas, a voz instrutiva e punitiva do Partido é propagada para toda a população oceânica. As teletelas são encontradas em praticamente todos os lugares, de maneira que esteja o indivíduo em casa, trabalhando, comendo ou dormindo a observação nunca é interrompida. Ainda que existam divisões hierárquicas dentro do próprio Partido, nenhum cidadão está livre do olhar frio da pequena placa de metal, mesmo aqueles que têm como função vigiar os seus vigilantes.

Decorrem desse processo dois aspectos fundamentais: primeiramente, o rígido controle exercido independentemente da posição ocupada pelo indivíduo evita, como salienta Foucault, a suposta concentração de poder nas mãos de um único sujeito ou de uma determinada classe. Bentham enfatiza que "isso dá uma resposta, e uma resposta satisfatória, a uma das questões políticas mais intrigantes - quis custodiet ipsos custodes [quem guarda os próprios guardas]?” (BENTHAM, 2000, p. 27).

Em segundo lugar, o mecanismo de observação apresenta uma simplicidade funcional aliada a uma eficiência coercitiva aparente, uma vez que a consciência da suposta observação permanente condiciona os comportamentos individuais. Dessa forma, o Partido se torna onipresente e onisciente, como ilustram os inúmeros cartazes que ostentam a imagem do líder máximo do regime: “O Grande Irmão Zela Por Ti, dizia a legenda” (ORWELL, 2003, p. 5). O próprio Winston reconhece o efeito normalizador proporcionado pelo dispositivo de vigilância na sociedade oceânica:

Naturalmente, não havia jeito de determinar se, num dado momento, o cidadão estava sendo vigiado ou não. Impossível saber com que frequência, ou que periodicidade, a Polícia do Pensamento ligava para a 
casa deste ou daquele indivíduo. Era concebível, mesmo, que observasse todo mundo ao mesmo tempo. (ORWELL, 2003, p. 6).

Entretanto, assim como alerta Foucault, a vigilância é apenas um dos mecanismos que sustentam as sociedades disciplinares, sendo que na distopia orwelliana tal prerrogativa é facilmente verificável.

É preciso considerar que a estrutura social idealizada por George Orwell reúne aspectos dos poderes monárquicos e disciplinares, os quais constituem a utopia totalitária. Na Oceania, a violência não foi totalmente excluída do processo de manipulação e normalização dos indivíduos. Semelhantemente aos regimes centralizadores que marcaram o século XX, o controle é praticado por meio de coerções psicológicas, ideológicas e também físicas. Alguns críticos acreditam que a inclusão de procedimentos violentos no aparelho do Estado distópico deprecia o grau de estabilidade que supostamente deveria caracterizar esse tipo de modelo social. Jenni Calder comenta que

When Huxley wrote to Orwell after reading Nineteen Eighty-Four he suggested [...] that a more authentic picture of the future would not contain the violence of Orwell's book. It would not be necessary, for men had the means to control the mass of humanity through influencing their minds. That kind of power made the punishment of their bodies unnecessary. ${ }^{15}$ (CALDER, 1976, p. 9).

A respeito da crítica de Huxley, acreditamos que dois pontos devem ser considerados. Em primeiro lugar, a Oceania é uma sociedade em pleno e acelerado desenvolvimento, sendo a perfeita consolidação do poder ainda um objetivo a ser alcançado. Se assim não o fosse, toda a narrativa se tornaria inviável, uma vez que a consciência individual de Winston seria impossível. Consequentemente, o regime ainda conserva alguns traços arcaicos do ponto de vista punitivo. Além disso, a violência representada na obra não se destina exclusivamente à punição. A liberação dos impulsos violentos dos indivíduos é canalizada para pessoas ou elementos de acordo com o desejo do Ingsoc. Tal iniciativa, ao contrário de promover contestação ou revolta, solidifica ainda mais o poder estatal e a homogeneização ideológica da população ao fornecer espaço e objetivos para os instintos violentos. Nesse sentido, a tecnologia, a violência e a disciplina se complementam enquanto mecanismo de condicionamento individual. Calder deixa claro que:

It is not just the paraphernalia of telescreens and Thought Police that exercise that power, but something much deeper and more dangerous. It

\footnotetext{
${ }^{15}$ Tradução livre: Quando Huxley escreveu para Orwell depois de ter lido 1984 sugeriu [...] que uma representação do futuro mais autêntica não conteria a violência do livro de Orwell. Não seria necessário, uma vez que os homens possuíam os meios para controlar a massa humana por meio da influência sobre suas mentes. Esse tipo de poder torna a punição de seus corpos desnecessária.
} 
is a psychological power, a power that can, for instance, induce Winston to participate in the Two Minutes Hate with every fibre of his being in spite of his resistance to it. ${ }^{16}$ (CALDER, 1976, p. 20).

Ainda que o protagonista lute contra os instintos violentos deliberadamente suscitados pelos dispositivos do Partido, ele não consegue evitar certo grau de contaminação pela rigidez e pela intolerância que domina a sociedade. $O$ obscuro desejo da personagem de esmagar o crânio de Júlia, assim como a sua prontidão em cometer um assassinato caso fosse descoberto caminhando pelo bairro dos proles, são exemplos da poderosa influência psicológica do Ingsoc.

It is not only under the influence of the Two Minutes Hate that images of violence dominate his mind. He has been thoroughly infected by the Party ethic, primed to accept O' Brien ultimate justification of power, in spite of the fact that he is trying so hard to rediscover his humanity. ${ }^{17}$ (CALDER, 1976, p. 21).

Possivelmente, o exemplo mais claro dessa manipulação psicológica em 1984 é a prática do duplipensar. Por meio desse instrumento de autocoerção individual, o Partido fragmenta o exercício do poder e o coloca sob a responsabilidade do próprio sujeito. Dessa maneira, cada cidadão é constantemente testado em relação a sua ortodoxia por meio das recorrentes alterações de fatos e dados que exigem a imediata e inequívoca aceitação de todos os indivíduos. Com isso, o processo de reconstrução da história se torna possível e viabiliza não apenas a perenidade do regime, mas também a o poder absoluto do Partido. Como afirma Gilles Deleuze, "os confinamentos são moldes, distintas moldagens, mas os controles são uma modulação, como uma moldagem autodeformante que mudasse continuamente, a cada instante, ou como uma peneira cujas malhas mudassem de um ponto a outro" (DELEUZE, 1992, p. 221).

Finalmente, é preciso considerar a importância dada por Foucault à produção de saber com base nos mecanismos coercitivos. Para o autor, o processo de análise a partir do controle tem raízes ainda nos regimes monárquicos e o seu progressivo desenvolvimento permitiu a ascensão das sociedades disciplinares. "O quadro, no século XVIII, é ao mesmo tempo uma técnica de poder e um processo de saber. Trata-se de organizar o múltiplo, de se obter um instrumento para percorrê-lo e dominá-lo" (FOUCAULT, 1984, p. 135).

Assim, surge outra característica das estruturas sociais disciplinares: o poder epistemológico. A consequência direta desse aspecto é a formação de um processo constante de

\footnotetext{
${ }^{16}$ Tradução livre: Não é apenas a parafernália de teletelas e a Polícia do Pensamento que exercem esse poder, mas algo muito mais profundo e mais perigoso. É um poder psicológico, um poder que pode, por exemplo, induzir Winston a participar nos Dois Minutos de Ódio com cada fibra do seu ser, independentemente de sua resistência a isso.

${ }^{17}$ Tradução livre: Não é apenas sob a influência dos Dois Minutos de Ódio que imagens de violência dominam a sua mente. Ele foi completamente infectado pela ética do Partido, preparado para aceitar a justificativa final de O' Brien sobre o poder, independentemente do fato de ele estar lutando bravamente para redescobrir a sua humanidade.
} 
renovação, tanto dos mecanismos de controle quanto das práticas coercitivas que compõem o regime. Como afirma Foucault em A Verdade e as Formas Jurídicas:

É assim que os indivíduos sobre os quais se exerceu poder ou são aquilo a partir de que se vai extrair o saber que eles próprios formaram e que será retranscrito e acumulado segundo novas normas, ou são objeto de um saber que permitirá também novas formas de controle. É assim, por exemplo, que um saber psiquiátrico nasceu e se desenvolveu até Freud, que foi a primeira ruptura com ele. O saber psiquiátrico se formou a partir de um campo de observação exercida prática e exclusivamente pelos médicos enquanto detinham o poder no interior de um campo institucional fechado que era o asilo, o hospital psiquiátrico. (FOUCAULT, 1996, p. 122).

Dessa forma, fica claro que as sociedades disciplinares evoluem ininterruptamente a partir dos próprios dispositivos de poder utilizados, o que vem corroborar nosso prévio comentário sobre o processo contínuo de desenvolvimento da sociedade figurada em 1984. A personagem O' Brien, ao discorrer sobre o futuro da Oceania, enfatiza o processo de permanente aperfeiçoamento do controle social, o que nos leva a crer que a constante especialização dos mecanismos controladores constitui o único aspecto realmente perene na distopia orwelliana.

A espionagem, as traições, as prisões, as torturas, as execuções, os desaparecimentos jamais cessarão. Será tanto um mundo de terror quanto de triunfo. Quanto mais poderoso o Partido, menos tolerante: mais débil a oposição, mais rígido o despotismo. [...] Esse é o mundo que estamos preparando, Winston, um mundo de vitória após vitória, de triunfo sobre triunfo: infinda pressão, pressão, pressão sobre o nervo do poder." (ORWELL, 2003, p. 256).

À guisa de conclusão, retornemos à questão do lugar ocupado pelo romance 1984 no imaginário coletivo dos séculos XX e XXI. Ao figurar o seu universo distópico, Orwell se debruçou criticamente sobre as tendências centralizadoras e totalitárias da mundial história recente para delinear os contornos de um futuro aterrador, no qual a ordem substituiria totalmente a individualidade. Essa projeção não se concretizou. Ao menos no nível de radicalismo e eficiência imaginado por Orwell. Contudo, seria um suposto potencial messiânico a mais importante dentre as características do romance? A partir de nossa análise, acreditamos ser mais relevante a figuração de uma luta desigual e incessante de um ser humano pelo direito de sua própria identidade social, em um contexto que prega a uniformidade e a estabilidade a qualquer custo. Esse esforço, cada vez mais transcrito em anseios e lutas comunitárias, pode facilmente ser encontrado nos anais da história das décadas que seguiram a publicação de 1984. Em um século no qual o totalitarismo quase alcançou o status de utopia realizável, tal 
batalha pode representar muito, independentemente da violência ou da sutileza dos mecanismos controladores que a reprimem.

Qual seria então a herança do romance de Orwell depois de setenta anos de sua primeira edição? Há ainda espaço para as problematizações e preocupações do autor no imaginário dos leitores do século XXI? Um primeiro ponto a se considerar é que, em termos quantitativos, a produção de distopias aumentou vertiginosamente desde antes da virada do milênio e essa proporção se manteve desde então. A nosso ver, essa tendência crescente não se deve necessariamente a um maior grau de pessimismo generalizado. Seria possível argumentar que a criticidade dos sujeitos-produtores e sujeitos-leitores em relação ao seu meio social se tornou mais aguçada. Diretamente ligado a esse processo, surge o segundo ponto que objetivamos abordar. Se a multiplicação de distopias é um fato editorial e se, como vimos, o espelhamento do real é uma característica do gênero, podemos inferir (assim como escritores e receptores) que o universo experimental ainda reserva mecanismos de controle que, mesmo distintos em suas essências e modus operandi, aproximam-se em termos de funcionalidade e objetivos daqueles descritos por Orwell. A distopia do Grande Irmão não se tornou realidade. Mas isso não quer dizer que dinâmicas de apagamento de individualidades, dispositivos de coerção de sujeitos, técnicas de manipulação de informações, estruturas de vigilâncias e discursos autocráticos de ordem não estejam em pleno funcionamento. E se as intenções utópicas desses aparelhamentos não estão plenamente consolidadas no presente, não se deve jamais ignorar o potencial distópico latente que elas preservam. No amplo horizonte da recepção literária, as distopias reafirmam esse alerta. E 1984 nos lembra de que, entre as encruzilhadas dos idílios e dos pesadelos, o Grande Irmão sempre está a nos observar.

\section{REFERÊNCIAS}

ARENDT, H. Ideology and Terror. In: The Burden of Our Time. London: Allen and Unwin, 1967. BENTHAM, J. O Panóptico. Tomaz Tadeu da Silva (org.) Belo Horizonte: Autêntica, 2000. BERLIN, I. Limites da Utopia: Capitulos da História das Ideias. São Paulo: Companhia das Letras: 1991.

CALDER, J. Huxley and Orwell: Brave New World and Nineteen Eighty-Four. London: Edward Arnold, 1976.

CANOVAN, M. Arendt's Theory of Totalitarianism. In:ARENDT, H. The CambridgeCompanion to Hannah Arendt. Edited by Dana Villa. Reino Unido: Cambridge University Press, 2000 CLAEYS, G. (editor). The Cambridge Companion to Utopian Literature. London: Cambridge University Press, 2010.

CLAEYS, G. Utopia: A história de uma ideia. Trad. Paulo Barros. São Paulo: Edições SESC, 2013. 
DELEUZE, G. Conversações. Rio de Janeiro: Editora 34, 1992.

ELLIOT, R. C. The Shape of Utopia: Studies in a Literary Genre. Chicago: University of Chicago Press, 1970.

FOUCAULT, M. Microfísica do Poder. Rio de Janeiro: Graal, 1981.

FOUCAULT, M. A Verdade e as Formas Jurídicas. Rio de Janeiro: Editora Nau, 1996.

FOUCAULT, M. Vigiar e Punir. Rio de Janeiro: Vozes, 1984

LIMA, L. C. Sociedade e Discurso Ficcional. Rio de Janeiro: Guanabara, 1986.

MEYERS, J. A Reader's guide to George Orwell. London: Thames and Hudson, 1975.

ORWELL, G. 1984. São Paulo: Editora Nacional, 2003.

ORWELL, S.; ANGUS I (org.). The Collected Essays, Journalism and Letters of George Orwell: As I Please 1943-1945. Volume 03. New York: Harcourt, 1968.

RABKIN, E. S. The Fantastic in Literature. New Jersey: Princeton University Press, 1977.

SCHOLES, R.; RABKIN, E. S. Science Fiction: History, Science, Vision. New York: Oxford University Press, 1977.

SZACHI, J. As Utopias ou a Felicidade Imaginada. Rio de Janeiro: Paz e Terra, 1972.

Recebido para publicação em 2 abr. 2019. Aceito para publicação em 22 jun. 2019. 